\title{
Movement as a critical concept in model generation to attain wholeness
}

\author{
Charlene Downing ${ }^{a, *}$, Marie Poggenpoel ${ }^{b}$, Chris Myburgh ${ }^{c}$ \\ ${ }^{a}$ University of Johannesburg, Department of Nursing Sciences, John Orr Building, South Africa \\ ${ }^{\mathrm{b}}$ Department of Nursing Science, Faculty of Health Sciences, University of Johannesburg, South Africa \\ ${ }^{c}$ Department of Educational Psychology, Faculty of Education, University of Johannesburg, South Africa
}

\section{A R T I C L E I N F O}

Article history:

Received 11 July 2016

Accepted 25 January 2017

Keywords:

Wholeness

Model generation

Movement

Qualitative research

\begin{abstract}
A B S T R A C T
Movement is an integral aspect of daily living. Movement allows the human being to express, find meaning and reflect a part or the whole of the unfolding of the stories of their lives. The essence of the dialogue is the movement towards caring and healing between the professional nurse and the individual.

The purpose of this research is to develop, describe, evaluate and provide guidelines for the operationalisation of a model as a framework of reference for nursing to facilitate the individual faced with mental health challenges as an integral part of wholeness.

A model was generated to facilitate the engagement of self through movement, which contributes to and manifests in a mindful way of living to promote mental health as an integral part of wholeness. The findings of the study are applicable to the world of nursing practice, nursing education and research.
\end{abstract}

(c) 2017 The Authors. Publishing services by Elsevier B.V. on behalf of Johannesburg University. This is an open access article under the CC BY-NC-ND license (http:// creativecommons.org/licenses/by-nc-nd/4.0/).

\section{Introduction}

Movement is central to life and adds meaning to the multidimensional nature of humans. Movement is vital in the caring and healing actions in nursing and is important in rendering quality care. Movement occurs between both the nurse and the patient (Winther, Grontved, Graveson, \& Ilkjaer, 2014). Individuals with mental health issues experience a wide range of obstacles in taking care of themselves and being part of a community as well as being a patient in a healthcare system. Coping with the demands of everyday living (intrapersonal, interpersonal and environmental) is taxing and impairs the functioning of the individual at various levels. The profession constantly asks the nurse to live and see patients as unique and valuable human beings (Porter, O'Halloran, \& Morrow, 2011). The patient and professional nurse engagement occurs to assist patients in finding meaning and purpose in their lives, to assist patients to find and maintain meaningful relationships, and to engage in daily decision-making in such a way that it enhances their quality of life (Porter et al., 2011). Professional nurses are thus key in the promotion and

\footnotetext{
* Corresponding author.

E-mail address: charlened@uj.ac.za (C. Downing).
}

Peer review under responsibility of Johannesburg University. 
attainment of the well-being of the people they care for (Watkins, Roos, \& Van Der Walt, 2011).

According to McElligott (2010:253), healing involves and requires both the individual and the professional nurse to play an active and integrated role. The healing occurs when both the individual and the professional nurse are involved within the caring and a unity of being is present during the interaction (Finfgeld-Connett, 2008). According to Maclaren (2009), the primary focus of nursing interactions is on the creation and manifestation of a space within which the patient feels understood and heard. When providing quality patient care, the professional nurse affirms the self-worth of the patient as well as validates their sense of wholeness (Maclaren, 2009).

The objectives of the research study were to develop and describe a practice-level model based on the experiences of individuals with mental health challenges. Belly dancing, a unique form of movement, was examined because belly dancing is a cultural art form with outstanding results and rewards, both internally and externally for every participating woman. Through belly dancing the dancers learn new wisdom and rituals, and are physically and emotionally aware of the culturally acquired conditioning, repression and blockages (Al-Rawi, 1999). This form of movement was used to construct guidelines for the operationalisation of a model as a frame of reference for nursing to facilitate the individual's mental health as an integral part of wholeness. The aim of the article is to describe the construction of a model for application within the practice of mental health nursing based on the single core concept of movement.

\section{Methods used for developing the model}

A theory generation strategy was used based on a qualitative, exploratory, descriptive and contextual approach. Theory development is the overall goal of theory generation designs (Walker \& Avant, 2011). According to Chinn and Kramer (2011), in the theory generative approach scientific knowledge is accumulated specifically and in an orderly fashion to fulfill a goal. Theory generation as a whole is more than the isolated description of identified and related events. Theory generation contains identifiable components such as concept identification, classification and definition of concepts. Furthermore, theory generation proposes relational statements between concepts, and guides the growth and enrichment of the emergent theory. The intrinsic value of such a generated theory lies in the value-adding dimension to the body of knowledge of nursing (Walker \& Avant, 2011).

Walker and Avant (2011) and Chinn and Kramer (2011) proposed four levels of theory generation: meta-theory, grand theory, middle range theory and practice theory. These levels identify the breadth and depth of the scope of theory development. The focus of this study was on the level of practice theory since the foundation of the model needed to be developed. The development of the practice theory needed to be orientated to the realities of nursing practice and show relevance to the scope of nursing care.

In the empirical phase of concept identification, a purposive sample was used which consisted of eight individuals participating in belly dancing in South Africa. Data was collected using in-depth phenomenological, semi-structured, individual interviews until data saturation was reached. Data analysis was conducted by means of thematic coding to identify themes.

\section{Definition of the concept of movement}

The main concept of "facilitation of engagement of self through movement in a mindful way of living to promote wholeness" can be analysed by defining the individual aspects of the concept of movement.

\section{Dictionary definitions of the word movement}

The Concise Oxford Dictionary (Soanes \& Stevenson, 2008) defines the word "movement" as an act of moving, a certain activity that occurs within a particular time, and which can be related to a group of people working in union to bring about a change or development (Stevenson, 2014). In various dictionaries and thesauri the relationship between music and movement is often referenced. There is thus a sense of synergy between music and movement. Synergy occurs between movement and a musical composition. The word "movement" is also used within the context of emotion, with specific reference to the phrase of "making an impression" and this can be seen, lived and felt within the movement in the internal world (Merriam-Webster, n.d).

The expression to be a "mover and shaker" describes a person who has the dynamic ability to initiate situations and influence or has the power to influence people. This phrase was coined in the movie Music and Moonlight by O'Shaughnessy in 1874 (Soanes \& Stevenson, 2008). The relationship between movement, music and the emotions played a fundamental role in the telling or unfolding of the central storyline. Such relationship indicates a triangulation of the three components where movement is central to the enhancement of emotions and music, and can represent the "real" music heard or the "music" of life that unfolds for each person.

In summary, according to the dictionary definition, there is a close relationship between:

- the occurrence of movement;

- a change of state and/or opinion; and

- an action that initiates or advances a progress or plan.

\section{Subject literature definitions of movement}

Roux, Edward, and Hlongwe (2007) write that, "Flowing water never stagnates, and the hinges of an active door never rust. This is due to movement. The same principle applies to essence and energy. If the body does not move, essence does not flow. When the essence does not flow energy stagnates." Movement allows the body to become one with the life of the individual. Movement allows the individual to live the experience, realise their full potential or become the beautiful picture of the display of all the emotions that are embedded within the movement, whether this 
is joy, or any other story that is being told through the movement. There can be a variety of recognitions of feelings and experiences associated with the movement, for example joy and belonging, which can manifest the dynamics which bring about change within the individual.

In the experiential world movement can become an inner part of the creation of self; in the dancing environment a climate of acceptance of the self is created (Smith, 2011). The dancing environment facilitates acceptance by being a non-threatening environment (Jennings, 2010). The continual process of moving forward can encourage the individual to move towards selfacceptance, and this dynamic process promotes a process of change and the capacity to live in a mindful way. By moving, it is suggested that individuals can experience wholeness in themselves and their internal and external environment.

Newman (Alligood, 2010; George, 2002) cites various meanings of movement with specific relation to nursing theory and nursing practice. She states that movement is a reflection of consciousness, and that where the inner being finds itself is a reflection of the dynamic balance of the individual's relation to self and the external environment. The pattern of movement depicts the wholeness of individuals and their understanding of meaning and their relationships (Smith, 2011).

Table 1 provides a summary of the essential and related criteria for the word "movement".

\section{The process of theory development/ generation}

Theory generation proceeded according to the four steps described by Chinn and Kramer (2011) as discussed below.

\section{Step 1 Concept Analysis}

The analysis of concepts played a pertinent role in theory generation. Walker and Avant's approach to concept identification was used in this step (Walker \& Avant, 2011). It required the researcher to adhere to clear and precise definitions of the identified concepts. This allowed the researcher to attain and construct an accurate and true reflection for the theoretical foundation of the development of the model (Tofthagen, 2010; Walker \& Avant, 2011). In this phase, concepts pertinent to the lived experience of the belly dancer were isolated. The analysis proceeded from concept identification to classification and finally, concept definition.

\section{Definition and classification of concepts}

The main concepts of the study emerged during the process of identifying key features of movement. However, the main and related concepts still needed to be classified and defined. Walker and Avant's (2011) approach was used to define the main concepts, while related concepts were

\section{Table 1 - Essential and related criteria of "movement".}

\begin{tabular}{ll} 
Essential criteria & \multicolumn{1}{c}{ Related criteria } \\
\hline $\begin{array}{l}\text { Dynamic } \\
\text { Change }\end{array}$ & $\begin{array}{l}\text { - Flow of energy } \\
\text { - Internal and external environment } \\
\text { exchange }\end{array}$ \\
\hline
\end{tabular}

classified by using the survey list as an approach developed by Dickoff, James, and Wiedenbach (1968).

Walker and Avant's (2011) approach firstly involved a thorough perusal of both dictionary and subject literature definitions of the main concepts. Secondly, the definition of the main concepts was synthesised from the preceding perspectives. Walker and Avant (2011) state that "in many cases the critical attributes and empirical referents will be identical". This means that the themes from the data, the dictionary and subject literature perspectives were integrated into a definition of the main concept thereby meeting the requirements of Tofthagen (2010) that a definition:

- should state the essential attributes of the concept;

- should not be circular, should not be either too broad nor too narrow; should not be expressed in ambiguous, obscure or figurative language; and

- should not be negative where it can be affirmative.

\section{A description of the process of facilitation of engagement of self through movement in a mindful way of living to promote wholeness}

The survey list consists of six items which include the agent, recipient, context, procedure, dynamics, and terminus which are described as follows:

- The agent or facilitator in this study is the professional nurse. The professional nurse is enabled by ways of understanding and acquired skills to create an understanding of themselves in the role and capacity of facilitation. The professional nurse is enabled to understand and try to know the world of the individual with mental health challenges (Biley \& Galvin, 2007; Helin \& Lindstrom, 2003). The primary focus of the facilitator is the individual with mental health challenges and gaining an understanding of the individual. The healthcare environment sees clinical practice as the immediate environment in which to provide comfort, healing and meaning to the individual with mental health challenges within the physical, emotional, mental and spiritual needs identified. The professional nurse is the main agent within the caring and healing relationship with the individual with mental health challenges. The professional nurse integrates the technical aspects of caring with the knowing of the individual (Biley \& Galvin, 2007). The environment of engagement allows the individual with mental health challenges to move through the process of unawareness to awareness to enable empowerment of self in order to achieve mindful living. The professional nurse is thus empowered to move towards a deeper sense of meaning of how to find balance and engage with the individual with mental health challenges; and the professional nurse can thus be seen as a unique human in the context of caring and healing. During this interaction the professional nurse is present and her presence allows her to be authentic and show realness in the interaction to bring about a 
mindfulness of living within the lives of self and of individuals with mental health challenges (Downing \& Hastings-Tolsma, 2016; Iseminger, Levitt, \& Kirk, 2009).

- The immediate recipient of the activity is the individual with mental health challenges. The professional nurse assists the individual with mental health challenges to facilitate mental health as an integral part of wholeness through movement. The professional nurse thus explores the metaphor of dance through interrelating nursing, caring and healing. The support and encouragement of the professional nurse and the relationship with the patient are critical in the activation of the process that will lead the individual with mental health challenges from unawareness to awareness in order to facilitate and attain a mentally healthy lifestyle. The focus of the study emphasises the combination of arts and human science to allow for the integration of the living world and clarify the meaning of human existence and being-in-the-world (Biley \& Galvin, 2007). The facilitator, the professional nurse, is seen as the main agent within the procedure whereby the process of awareness is facilitated. During the activity the professional nurse engages with the individual with mental health challenges to facilitate mental health as an integral part of wholeness. The relationship is based on the openness and honesty within the interaction between professional nurse, the individual with mental health challenges and the healing and caring environment. The individual with mental health challenges is assisted within the interaction to explore and move through issues of self. Movement allows the gaining of a greater understanding of self, and in turn a process of awakening takes place that leads to a mindful way of living. During the journey the dancer "steps" into the unknown and, through a process of familiarisation and participation, thus attains greater skills over time. These steps are similar to the process from unawareness to awareness, from unknowing to knowing/mindfulness, and so the process of engagement with the self leads to mindfulness in living. The procedure that unfolds facilitates a sense of mindfulness in the daily activities and living of the participants. The procedure is seen as the relationship or the interplay that happens or transpires between the agent and the receiver.

- The individual with mental health challenges used belly dancing which served as a conduit in their search for enrichment of self, which continually grew in richness. Belly dancing is an activity of movement that was used as an instrument in facilitating mental health within individuals with mental health challenges. The process of facilitating the self allowed and created an interaction through belly dancing to further the development of self and encourage a mindful way of living so that the individuals were guided towards developing a wholeness of living. The professional nurse thus needs to be present with the individual and facilitate the movement towards mental health as an integrated part of wholeness. Being with the patient allows the professional nurses to use their extensive knowledge of the individual and allows them to be aware and alert to the needs of the individual (Iseminger et al., 2009). The professional nurse should thus strive to focus on the interaction with the individual with mental health challenges and the development of a trusting relationship to enhance the further development of the caring relationship. Watson (1988) indicates the development of an interaction that shows interrelatedness and connectedness to self-knowledge, self-caring, self healing and healing within relationships with self and other (Kniesl \& Trigoboff, 2013). The context is the area in which the facilitation and interaction will take place. The interaction may be found in a variety of clinical settings, for example in any mental healthcare service. The context can be inclusive of the individual, family and the community. The context can be seen as quite unique as the facilitator plays a vital role in the internal and external environment, balancing the two environments in order to move to the wholeness of the individual with mental health challenges. The exchange happens at the personal and intra-personal level of the individual. The context therefore is the movement and interaction between the professional nurse and the individual with mental health challenges. Current literature refers to the concept of healthy workplaces with regard to the health beliefs, values and practices of professional nurses, other care providers and patients (Stitchler, 2009). The health levels of the professional nurses are critical for the effect and nursing outcome in the care rendered to patients and other healthcare members. The goal of nursing is to foster a context for professional nurses to find meaning and purpose in their work. The professional nurse thus needs to find enjoyment in the work.

- Terminus refers to the outcome of the intervention. The outcome is the facilitation of self to enhance a mindful way of living to facilitate mental health as an integral part of wholeness of the individual within lived environments. Wholeness can be described as the integrated part of the larger living of the individual. The individual is participating in a process of movement from a position of unawareness to awareness. The discovery of wholeness through the living of our body and the meaningful integration into daily life restores the richness of the experience and reveals the truth of self. The meaningful engagement helps the individual with mental health challenges to attain mental health in an integrated way.

\section{Step 2 Construction of Relationship Statements of the Model}

The next step of the theory generation strategy is the construction of relationship statements of the model. A few pertinent statements are presented:

- The individual with mental health challenges engages in a partnership with the professional nurse through whom they are empowered to have an appreciation of themselves through movement and experiences 
leading to a deeper sense of themselves and a change can be initiated.

- The movement is a continuous and dynamic process with meaningful manifestations in life to experience mental health as a transformative and changing process to being mindful in everyday living.

- An ongoing process nurtures the increasing confidence and appreciation of beauty, and movement serves as a vehicle for realising a sense of self in the present and as a presence in the moment.

- The mindfulness of living is embodied in the coalescing of the unique sense of authentic self, movement, mental health and wholeness.

\section{Step 3 Structure and Process Description of the Model}

In the first phase (Fig. 1) the first steps are taken in the facilitative relationship between the individual with mental health challenges (the recipient) and the professional nurse. The engagement or getting to know one another is the beginning of the process towards bringing about changes or changing the current essence of being. This created space of empowerment and engagement allows the self of the individual with mental health challenges to prepare for the exploration of new experiences and new learning to occur and getting to know new movements in the living experiences. The newness in itself may lead the individual to invent, create and enjoy the newness or differentness.

In this phase the individual with mental health challenges expresses the desire or wish to participate in the belly dancing environment. The act of learning to belly dance is the starting point for the individual with mental health challenges on this journey. At this stage the individual is unaware of the process of wholeness that will start to unfold within the self during the belly dancing.

The individual with mental health challenges thus engages as the recipient in the building of the relationship and the professional nurse as the agent within the initial stages of trust. They each allow themselves to be engaged within the new environment of getting to know each other. The interaction allows for reflection and making meaning during the initial engagement.

The professional nurse is seen as the driving force within the process of engagement. The professional nurse offers assistance and creates an empowering environment to

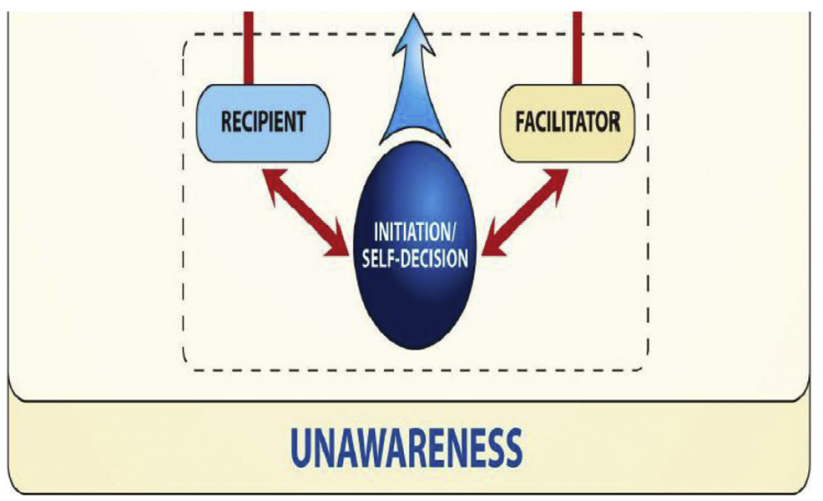

Fig. 1 - Phase one: Initiation of facilitation of self. further enable the individual with mental health challenges. The empowering environment makes it easier for the individual with mental health challenges to engage more deeply in this facilitative engagement. The professional nurse provides the individual with mental health challenges with the instrument (i.e. the self of the individual) to move more deeply into the self-discovery process. These are the initial steps of movement where the process is initiated to assist the individual with mental health challenges in gaining mindfulness of living as an integrated part of mental health. The professional nurse shares knowledge and experiences with the individual with mental health challenges in the "getting-toknow" phase. The individual with mental health challenges seeks the nurse out to share the knowledge and experiences in an environment that is understanding, open and inviting.

In the second phase (Fig. 2), the professional nurse creates a safe and empowering environment for the journey to continue. The creation of the enabling environment is important for the internal and external movement to occur. This dynamic change or movement needs to assist the individual with mental health challenges whereby the process of integrating the self in order to gain a deeper realisation of self is initiated. The partnership with the professional nurse acts as the catalyst to stimulate and bring about newness and growth in the individual with mental health challenges. The involvement and assistance are vital dimensions in the relationship between the nurse and the individual with mental health challenges and can bring about dynamic change. The dynamic changes need to be sustained by the individual with mental health challenges in everyday living to promote mental health as an integral part of wholeness of the person.

This involvement leads to the dynamic changes within the individual with mental health challenges in all dimensions of the self, to further enhance and facilitate the process of movement to promote and assist the mindfulness of living as an integral part of living to promote wholeness. The individual with mental health challenges is thus taking steps towards being present and being a presence in everyday life and being more authentic and real in living. The individual with mental health challenges thus creates a world of choice and embarks on the journey to choose a path of movement to explore deeper meaning and a sense of self, to be a more integrated in the self and thus find completeness of unity. The self is

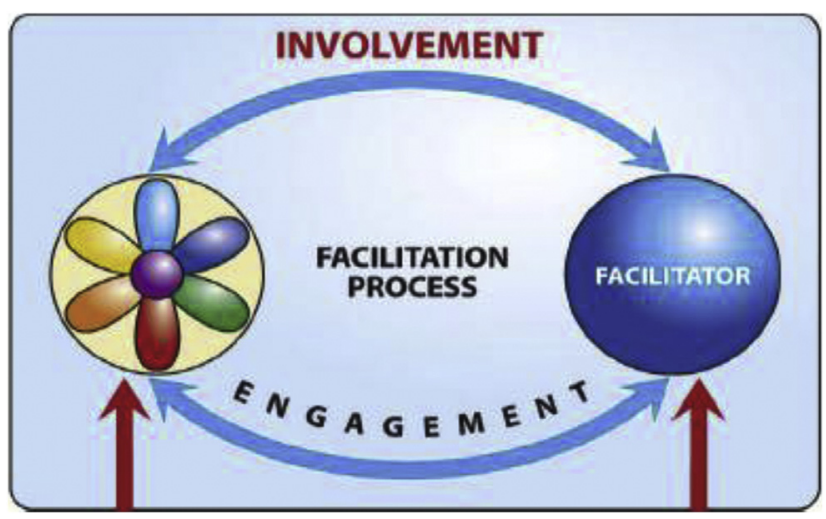

Fig. 2 - Phase two: The facilitation process of engagement and movement. 
described in the model (Fig. 3) as an individual with mental health challenges who is participating within a facilitative engagement with the professional nurse.

The person is seen as a unique and integrated being. The wholeness of the individual with mental health challenges is thus seen as greater than the sum of the parts. The parts that are referred to in this study are the physical, social, psychological, emotional, mental and spiritual parts that form the wholeness of the individual.

In the third phase (Fig. 4), the process of being more present and living with being present and having presence in daily living becomes part of the personal knowledge of the individual with mental health challenges.

Personal knowing is deeply rooted within the spiritual experiences and living of the individual. The words "spirit" and "spiritual" are defined by the life journey of discovering meaning and purpose in life and living (McCrae, 2012). The totality of the human spirit is seen and experienced in the complexity of its existence. The person is thus guided towards being more integrated and open towards experiences of wholeness.

Personal knowing and being part of spirituality brings meaning to the self-conscious awareness, and also nurtures the interconnectedness of the self during the challenges and the stages of confrontation during the journey of becoming conscious (Chinn \& Kramer, 2011; McCrae, 2012). The individual with mental health challenges is therefore on a journey to face the inner and outer challenges and vulnerabilities of life and bring about change, and more self-realisation in the awareness of living the realities of everyday life (Chinn \& Kramer, 2011; Elm \& Taylor, 2010).

The increased awareness leads to the individual to paying attention to being more open, to come to know what is within them and at the same time to show intentionality in this process. The movement of the individual with mental health challenges leads to further and deeper creations and experiences of mindfulness of living. The appreciation and acceptance of the self within the newness of the living environment creates a reflection to find a balance between the internal and external world. The individual with mental health challenges thus moves to finding a balance in the meaning of being open and spontaneous.

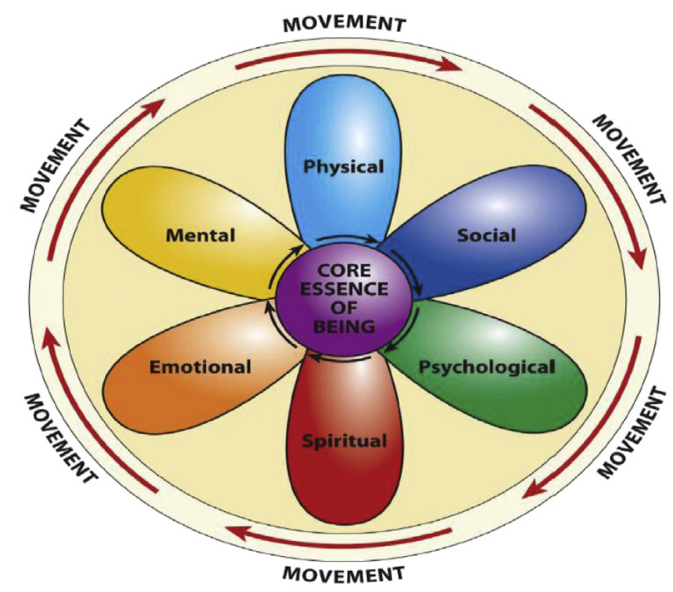

Fig. 3 - The wholeness of the individual with mental health challenges.

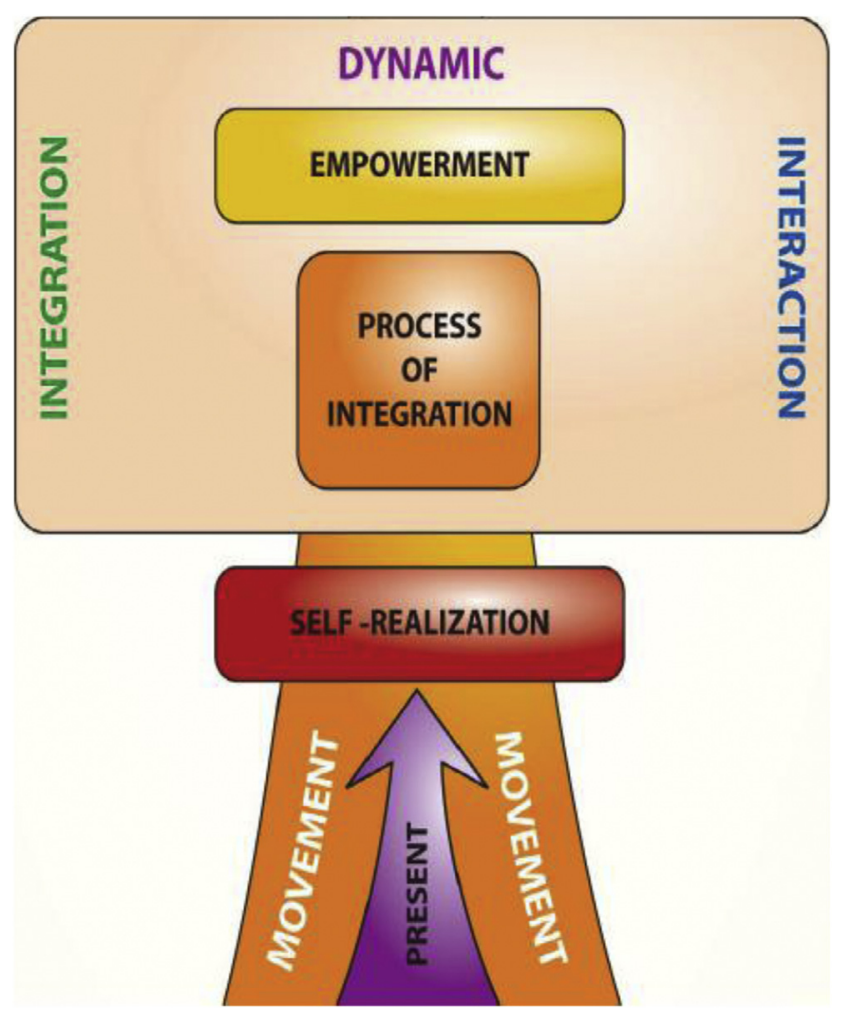

Fig. 4 - Phase three: The mobilisation of self through movement - internal and external.

The further enriched engagement leads the self to partially or fully realise potential. The interaction is deeply valued as meaningful and supports further changes for the individual with mental health challenges. The experiences contribute to the knowing of the individual with mental health challenges. The experiential knowing reflects the knowledge gained from the participation, the deepened awareness of intention and attention, and being part of the process of experiences with the connectedness in gaining full understanding of the meaning (Chinn \& Kramer, 2011).

The fourth phase (Fig. 5) depicts the penultimate result when the individual with mental health challenges is enjoying and is part of an enabled environment where they can feel the expression of life, be open and light, and enjoy the deeply rewarding work of living and being aware.

Ideally, this process should result is a state of mindfulness of living which will be continued throughout the life of the individual with mental health challenges in a continued striving to promote mental health as an integrated part of wholeness. Wholeness acts as a positive impetus to enhance further movement for a deeper meaning to consciousness and mindfulness of living.

As a result of this process the individual with mental health challenges feels and lives the deep meaning and authentic sense of self. The lived experiences are grounded in everyday living. The unfolding and knowing of the self guide the individual with mental health challenges to being present and experiencing presence in life. The individual with mental health challenges lives with acceptance and love, and leads to 


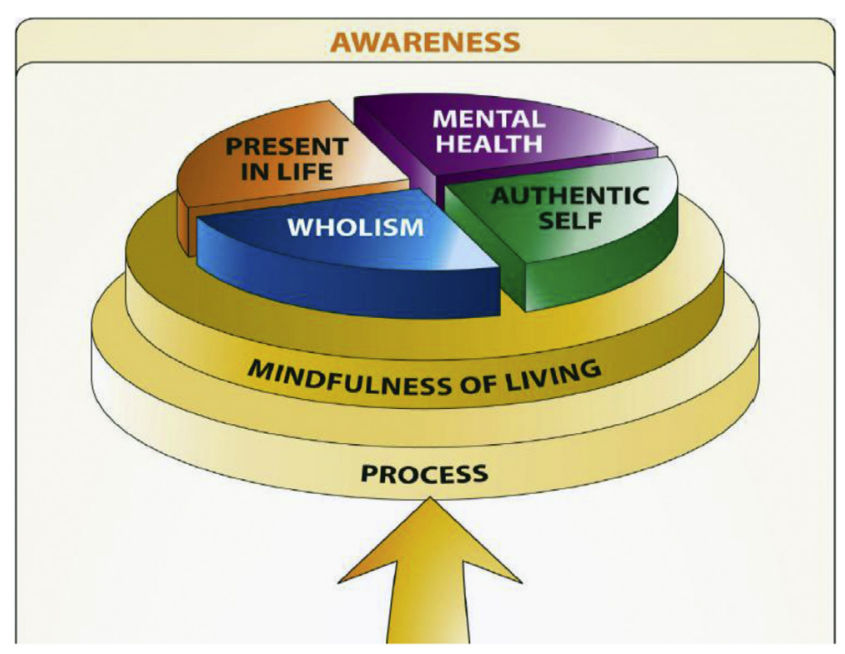

Fig. 5 - Phase four: The mindfulness of living to facilitate mental health as an integral part of wholeness.

being a mentally healthy person reaching out to attain and maintain wholeness in daily living activities.

According to Bumpus (2010), the movement towards wholeness is essential. Wholeness takes place through a continuous series of transformations. Transformations are the processes of individuations and move the individual to the realisation of the authentic self. The united being of the individual with mental health challenges allows the person to be one and united, and to enjoy the new life. The new life of facilitation of self-living with mindfulness brings about lifeenhancing and life-giving effects in the daily living of the individual with mental health challenges (Bumpus, 2010; White, 2014).

\section{A description of the guidelines for the operationalisation of the model}

The research findings and literature were used as the base for formulating the guidelines. The guidelines with specific strategies for interventions were developed to facilitate the process of engagement with self through movement to attain and maintain a mindful way of living as an integral part of mental health. The guidelines have the potential to contribute to the overall status of improvement of care rendered to self, other and the environment.

\section{Evaluation of the model}

Chinn and Kramer (2011) were used to evaluate the model. The model was evaluated by people involved during a presentation by the researcher as part of the current study. A written feedback report was given by all attendees in which they evaluated the model. The headings of the model evaluation were given to them. All the input and recommendations are described below as received by the researcher. The model was reviewed by using a set standard, well-researched and accepted method of evaluation as supported by Chinn and
Kramer (2011) - clarity, simplicity, scope and purpose, accessibility and clinical significance were used.

The participants at this presentation consisted of a number of people who had many years of experience in supervising doctoral candidates including one who had successfully supervised more than 100 post-graduate candidates in doctoral research. Three of the participants were professors. Two of these were in psychiatric nursing, with one being currently appointed in a teaching position of research methodology at all levels of teaching at a higher education institution and one in education. All participants were experts in qualitative and theory-generating methods.

All participants were academics representing the diversity of background and culture found in South Africa. Representatives from more than one higher education institution were present. Some of the participants were novice researchers and current doctoral candidates from higher education institutions. The participants were representative of various specialisation fields within nursing, including intensive care, public health, and psychiatric nursing. The participants were a reflection of the current world of practice in psychiatric nursing, nursing education and nursing research. The panel contributed to the critical analysis and evaluative processes of the model. The members evaluated the proposed model from a position of being informed and having an understanding of the nursing field or practice, in the know for utilisation of the model and providing critical feedback on application (Bumpus, 2010). Therefore the complexity and integrity of the exposure of the model was saturated.

\section{Discussion}

From the storyline and themes which emerged during the empirical stage of the research, the researcher gained an indepth and detailed understanding of the lived experience of the individual participating in belly dancing. The engagement was facilitated through movement and the experience of sharing and being an authentic being in constant interaction with the internal and external environment. The individual with mental health challenges participating in the process of engagement with the self through belly dancing created a new beginning for the self. Therefore the individual with mental health challenges moves within the process of facilitation to a greater sense of wholeness within themselves, with others and with their immediate and less-immediate environment. The movement occurs in harmony with the self and involves a process of engagement to create an authentic and genuine self. The discovered self thus engages in a process of healing and as a result starts participating in the creation of newness in life. The individual with mental health challenges embraces the wholeness that is intimately related to a mindfulness in living. The individual lives in harmony with the world to facilitate mental health as an integral part of wholeness (White, 2014). Wholeness of the person and continual interaction with the person's environment is purported in the Theory of Integral Nursing by Dossey. Shea and Frisch (2016) compares the Theory of Integral Nursing by Dossey in relation to the original theoretical source, which is the work of Wilber's integral theory. The inclusiveness of the whole person and the process of 
continual interaction with the environment is emphasized as one of the aims of Dossey (Shea \& Frisch, 2016).

In nursing practice, healing and caring are the core elements. The concepts of healing and caring find their initial meaning in the writings of Nightingale. According to McElligiott (2010:251), Nightingale saw healing in terms of a wholistic perspective of togetherness of all aspects of the person, mind and spirit. Thus by integrating person, mind and spirit the professional nurse aims at achieving and maintaining an integrated balance. In this study the meaning of movement for the individual was explored to describe the inner and outer healing of the participant. The more the individuals with mental challenges showed evidence of caring for themselves, the more healing happened within them and their environment.

Professional nurses experience changes and happenings within their lives, and they need to be enabled to see and experience change as a constant and ongoing process (Alligood \& Tomey, 2010, p. 680). The empowerment of the professional nurse lies at the heart of caring for self and the patient. The professional nurse and the patient are united within a dance. They are the dancers and dancing partners in the dance. According to Alligood and Tomey (2010:681), when effective nursing is happening, there is an inability to separate the dancer from the dance. Caring is seen as being part of all our existence and a means of enriching the human being to a power of resourcefulness with a mindfulness of living (Alligood \& Tomey, 2010, 679-680).

\section{Limitations}

The theory therefore remains to be viewed as substantive until such testing in a wider scope is done. The model and the guidelines have not been operationalised in clinical nursing practice, nursing education or nursing research.

\section{Conclusion}

The discussion above provides a description of the steps that were utilised in the development of the model for the facilitation of mental health through belly dancing as movement. These steps included placing the concepts in relationship, the description of the model, and the vignette as application of the model.

It is recommended that further research on the current model be implemented. Additional study will enable the model to be refined and truth value in clinical practice can be tested.

\section{R E F E R E N C E S}

Al-Rawi, R. (1999). Belly dancing: Unlock the secret power of an ancient dance. London: Robinson.

Alligood, M. R. (2010). Nursing theory utilization \& application (4th ed.). Missouri: Elsevier.

Alligood, M. R., \& Tomey, A. M. (2010). Nursing theorists and their work (7th ed.). Missouri: Elsevier.
Biley, F. C., \& Galvin, K. T. (2007). Lifeworld, the arts and mental health nursing. Journal of Psychiatric and Mental Health Nursing, 14, 800-807.

Bumpus, M. R. (2010). Awakening hidden wholeness: A Jungian view of Luke 10: 38-42. Journal of Psychology and Christianity, 29(3), 229-236.

Chinn, P. L., \& Kramer, M. K. (2011). Integrated theory \& knowledge development in nursing (8th ed). St Louis: Mosby.

Dickoff, J., James, P., \& Wiedenbach, E. (1968). Theory in a practice discipline, part 1: Practice oriented theory. Nursing Research, 17(5), 415-435.

Downing, C., \& Hastings-Tolsma, M. (2016). An integrative review of Albertina Sisulu and ubuntu: Relevance to caring and nursing. Health SA Gesondheid http://dx.doi.org/101016/j.hsag.2016.04. 002.

Elm, D. R., \& Taylor, S. S. (2010). Representing wholeness: Learning via theatrical productions. Journal of Management Inquiry, 19(2), 127-136. http://dx.doi.org/10.1177/ 1056492609360407.

Finfgeld-Connett, D. (2008). Concept synthesis of the art of nursing. Journal of Advanced Nursing. http://dx.doi.org/10.1111/ j.1365-2648.2008.04601.x.

George, J. B. (2002). Nursing theories the base for professional nursing practice (5th ed.). New Jersey: Prentice Hall.

Helin, K., \& Lindstrom, U. A. (2003). Sacrifice: An ethical dimension of caring that makes suffering meaningful. Nursing Ethics, 10(40), 414-427. http://dx.doi.org/10.1191/0969733003ne622oa.

Iseminger, K., Levitt, F., \& Kirk, L. (2009). Healing during existential moments: The "art" of nursing presence. Nursing Clinics of North America, 44, 447-459. http://dx.doi.org/10.1191/ 0969733003ne622oa.

Jennings, N. (2010). Defining a caring hospital by using currently implemented survey tools. Journal of Holistic Nursing, 28(3), 187-192. http://dx.doi.org/10.1177/08980101010369174.

Kniesl, C. R., \& Trigoboff, E. (2013). Contemporary psychiatric mental health nursing (3rd ed.). New Jersey: Pearson-Prentice Hall.

Maclaren, J. (2009). Health, healing and caring nurses: A reflection of SANE. On the Edge, 15.4 (2009). Academic OneFile. (Accessed 8 June 2011).

McCrae, N. (2012). Whither nursing models? The value of nursing theory of evidence-based practice and multidisciplinary health care. Journal of Advanced Nursing, 68(1), 222-229. http:// dx.doi.org/10.1111/j.1365-2648.2011.05821.x.

McElligott, D. (2010). The journey from concept to nursing practice. Journal of Holistic Nursing, 28(4), 251-259.

Merriam-Webster. (n.d). Retrieved November 13, 2014, from Merriam-Webster: http://www.merriamwebster.com/ dictionary/moverandshaker.

Porter, S., O'Halloran, P., \& Morrow, E. (2011). Bringing values back into evidence-based nursing. The role of patients in resisting empiricism. Advances in Nursing Science, 34(2), 106-118. April-June.

Roux, C. J., Edward, S. E., \& Hlongwe, M. M. (2007). Movement for life and health: African lessons. African Journal for Physical Education, Recreation and Dance, 18(1), 1-16.

Shea, L., \& Frisch, N. (2016). Wilber's integral theory and Dossey's theory of integral nursing an examination of two integral approaches in nursing scholarship. Journal of Holistic Nursing, 34(4), 244-252.

Smith, C. (2011). Integrative review of research related to Margaret Newman's theory of health as expanding consciousness. Nursing Science Quarterly, 24(3), 256-272.

Soanes, C., \& Stevenson, A. (2008). In C. Soanes, \& A. Stevenson (Eds.), Concise Oxford english dictionary (11th ed.). Oxford: Oxford University Press.

Stevenson, A. (2014). Oxford dictionary of english. Oxford: Oxford University Press. 
Stitchler, J. F. (2009). Healthy, healthful, and healing environments. A nursing imperative. Critical Care Nursing Quality, 32(3), 176-188.

Tofthagen, R. (2010). Rodgers' evolutionary concept analysis - A valid method for developing knowledge in nursing science. Scandinavian Journal of Caring Science, 24, 21-31. http:// dx.doi.org/10.1111/j.1471-6712.2010.00845.x.

Walker, L. O., \& Avant, K. C. (2011). In Strategies for theory construction in nursing (4th ed.). New Jersey: Pearson.

Watkins, K. D., Roos, V., \& Van Der Walt, E. (2011). An exploration of personal, relational and collective well-being in nursing students during their training at a tertiary education institution. Health SA Gesondheid, 16(1), 10. http://dx.doi.org/ 10.4102/hsag.v16i1.552. Art. \#552.

Watson, J. (1988). Nursing: Human science and human care. A Theory of Nursing. New York: National League of Nursing.

White, L. (2014). Mindfulness in nursing: An evolutionary concept analysis. Journal of Advanced Nursing, 282-294. http:// dx.doi.org/10.1111/jan.12182.

Winther, H., Grontved, S. N., Graveson, E. K., \& Ilkjaer, I. (2014). The dancing nurses and the language of the body. Journal of Holistic Nursing, 182-192. 